\title{
Job insecurity and risk of diabetes: a meta-analysis of individual participant data
}

Jane E. Ferrie PhD, Marianna Virtanen PhD, Markus Jokela PhD, Ida E.H. Madsen PhD, Katriina Heikkilä PhD, Lars Alfredsson PhD, G. David Batty DSc, Jakob B. Bjorner MD, Marianne Borritz MD, Hermann Burr PhD, Nico Dragano PhD, Marko Elovainio PhD, Eleonor I. Fransson PhD, Anders Knutsson MD, Markku Koskenvuo MD, Aki Koskinen MSc, Anne Kouvonen PhD, Meena Kumari PhD, Martin L. Nielsen MD, Maria Nordin PhD, Tuula Oksanen MD, Krista Pahkin PhD, Jan H. Pejtersen PhD, Jaana Pentti MSc, Paula Salo PhD, Martin J. Shipley MSc, Sakari B. Suominen MD, Adam Tabák MD, Töres Theorell MD, Ari Väänänen PhD, Jussi Vahtera MD, Peter J.M. Westerholm MD, Hugo Westerlund PhD, Reiner Rugulies PhD, Solja T. Nyberg MSc, Mika Kivimäki PhD; for the IPD-Work Consortium

\section{- Abstract \\ Background: Job insecurity has been associ- ated with certain health outcomes. We exam- ined the role of job insecurity as a risk factor for incident diabetes. \\ Methods: We used individual participant data from 8 cohort studies identified in 2 open-ac- cess data archives and 11 cohort studies partici- pating in the Individual-Participant-Data Meta- analysis in Working Populations Consortium. We calculated study-specific estimates of the association between job insecurity reported at baseline and incident diabetes over the follow- up period. We pooled the estimates in a meta- analysis to produce a summary risk estimate.}

Results: The 19 studies involved 140825 participants from Australia, Europe and the United States, with a mean follow-up of 9.4 years and 3954 incident cases of diabetes. In the preliminary analysis adjusted for age and sex, high job insecurity was associated with an increased risk of incident diabetes compared with low job insecurity (adjusted odds ratio [OR] 1.19, $95 \%$ confidence interval $[\mathrm{Cl}] 1.09-1.30)$. In the multivariable-adjusted analysis restricted to 15 studies with baseline data for all covariates (age, sex, socioeconomic status, obesity, physical activity, alcohol and smoking), the association was slightly attenuated (adjusted OR 1.12, $95 \% \mathrm{Cl} 1.01-1.24)$. Heterogeneity between the studies was low to moderate (age- and sexadjusted model: $I^{2}=24 \%, p=0.2$; multivariable-adjusted model: $P^{2}=27 \%, p=0.2$ ). In the multivariable-adjusted analysis restricted to high-quality studies, in which the diabetes diagnosis was ascertained from electronic medical records or clinical examination, the association was similar to that in the main analysis (adjusted OR 1.19, 95\% Cl 1.04-1.35).

Interpretation: Our findings suggest that selfreported job insecurity is associated with a modest increased risk of incident diabetes. Health care personnel should be aware of this association among workers reporting job insecurity.
$\mathrm{T}$ he increasing use of temporary contracts, zero-hours contracts and other forms of flexible employment have made job insecurity a feature of much previously secure employment in high-income countries. ${ }^{1}$ In addition to impacts on social circumstances, the health consequences of job insecurity are becoming recognized. ${ }^{2}$ Most evidence to date has relied on selfreported health outcomes, such as mental and physical health symptoms. ${ }^{3-5}$ In addition, an association has been reported between job insecurity and cardiovascular risk factors, such as dyslipidemia and weight gain, ${ }^{6}$ and a recent meta-analysis of individual data for 170000 workers showed an association between job insecurity and clinically verified incident coronary events. ${ }^{7}$

The prevalence of diabetes has increased steadily over recent decades, mostly owing to rising rates of overweight and obesity, and aging populations. ${ }^{8,9}$ There is indirect evidence to suggest an association between job insecurity and incident diabetes because previous work has shown an association between job insecurity and a subsequent increase in body mass index (BMI). ${ }^{6} \mathrm{~A}$ high BMI, in turn, is a strong risk factor for diabetes. ${ }^{10,11}$ However, a comprehensive search of the literature
Competing interests: None declared.

This article has been peer reviewed.

Accepted: Aug. 2, 2016

Online: Oct. 3, 2016

Correspondence to: Jane Ferrie, jane.ferrie@ bristol.ac.uk

CMAJ 2016. DOI:10.1503/ cmaj.150942 
(Appendix 1, available at www.cmaj.ca/lookup/ suppl/doi:10.1503/cmaj.150942/-/DC1) revealed no published studies examining the association between job insecurity and diabetes.

To address this gap in the literature, we undertook a meta-analysis of individual participant data from 8 cohort studies identified in 2 open-access data archives and 11 cohort studies from the Individual-Participant-Data Meta-analysis in Working Populations Consortium (IPD-Work Consortium). This approach allowed us to quantify the prospective association between job insecurity and subsequent incident diabetes in a large data set that included a wide variety of workers and countries.

\section{Methods}

\section{Study population}

We used individual-level data on job insecurity and incident diabetes for participants in 19 prospective cohort studies. Eight studies had openaccess data and were identified from collections at the Interuniversity Consortium for Political and Social Research (www.icpsr.umich.edu/icpsrweb/ ICPSR) and the UK Data Service (http:// ukdataservice.ac.uk/). ${ }^{12-19}$ Six of these studies involved general population samples. ${ }^{12-17}$ The other 2 included random samples of graduates from Wisconsin high schools and their siblings. ${ }^{18,19}$

The other 11 were European cohort studies ${ }^{20-30}$ participating in the IPD-Work Consortium. ${ }^{31}$ Four of the 11 studies included general population samples, ${ }^{20-22,24}$ and the rest involved either workers in the public sector or employees in private companies. ${ }^{23,25-30}$ Further details about the studies are available in Appendix 2 (www.cmaj.ca/lookup/ suppl/doi:10.1503/cmaj.150942/-/DC1).

For our meta-analysis, we included all women and men from the cohort studies who were in employment and free of diabetes at baseline and for whom complete data on job insecurity were available.

\section{Measurement of job insecurity}

Job insecurity was measured once at baseline in all 19 studies (Table 1). In the 8 studies from the open-access data sets, a question was asked about the level of insecurity in the person's current job or about satisfaction with job security. In the other 11 studies, a question was asked about the level of insecurity in the person's current job or about fear of layoff or unemployment. In all of the studies, the exposure was dichotomized into high or low job insecurity, as described previously. ${ }^{7}$

\section{Outcome measure}

The primary outcome was incident diabetes. The 8 studies from the open-access data sets defined incident diabetes over the follow-up period as the first self-report of diabetes. Of the 11 studies from the IPD-Work Consortium, the Whitehall II study $^{32}$ used the gold-standard World Health Organization criteria (a 75-g oral glucose tolerance test, with diabetes defined as a fasting glucose level of at least $7.0 \mathrm{mmol} / \mathrm{L}$, or a 2 -hour post-load glucose level of at least $11.1 \mathrm{mmol} / \mathrm{L}$, except for patients who had physician-diagnosed diabetes or who were using diabetes medication). The other studies from IPD-Work Consortium defined incident diabetes as the first record of diabetes, diagnosed according to the International Statistical Classification of Diseases and Related Health Problems 10th Revision code E11. This information was collected from hospital admission, hospital discharge and mortality registers that had a mention of diabetes in any of the diagnostic codes. In addition, in the Finnish studies, ${ }^{23,24,27}$ participants were defined as having incident diabetes the first time they were eligible for diabetes medication in the national drug reimbursement register. The date of diabetes diagnosis was defined as the date of the first record in any of the above-mentioned sources over the study follow-up period.

Participants with evidence of prevalent diabetes at baseline were excluded. Prevalent diabetes was defined on the basis of information from any of the following: hospital records, baseline oral glucose tolerance test results, self-report from the baseline questionnaire or drug reimbursement register (Finnish studies only).

\section{Assessment of covariates}

Confounders of the association between job insecurity and incident diabetes include age, sex, socioeconomic position, obesity, and reporting or common-method bias for studies in which both exposure and outcome are self-reported.

We were able to obtain the following data from almost all of the studies: participants' age, sex, socioeconomic status (based on participants' highest occupational grade or educational qualification and classified as low, intermediate or high) and obesity (defined as a BMI above 30). Other risk factors for diabetes, which may be associated with job insecurity and so act as potential confounders of the association, were physical activity (low, intermediate or high), smoking (current, former or never) and alcohol use (none, moderate, intermediate or heavy); these risk factors were similarly predefined and harmonized across the studies.

Data were not available on obesity from 2 studies, ${ }^{14,27}$ on alcohol use from 1 study $;{ }^{26}$ and on obesity, physical activity and alcohol use from another study. ${ }^{20}$ These 4 studies were excluded from the multivariable-adjusted models. 
Table 1: Measurement and prevalence of self-reported job insecurity in the included cohort studies

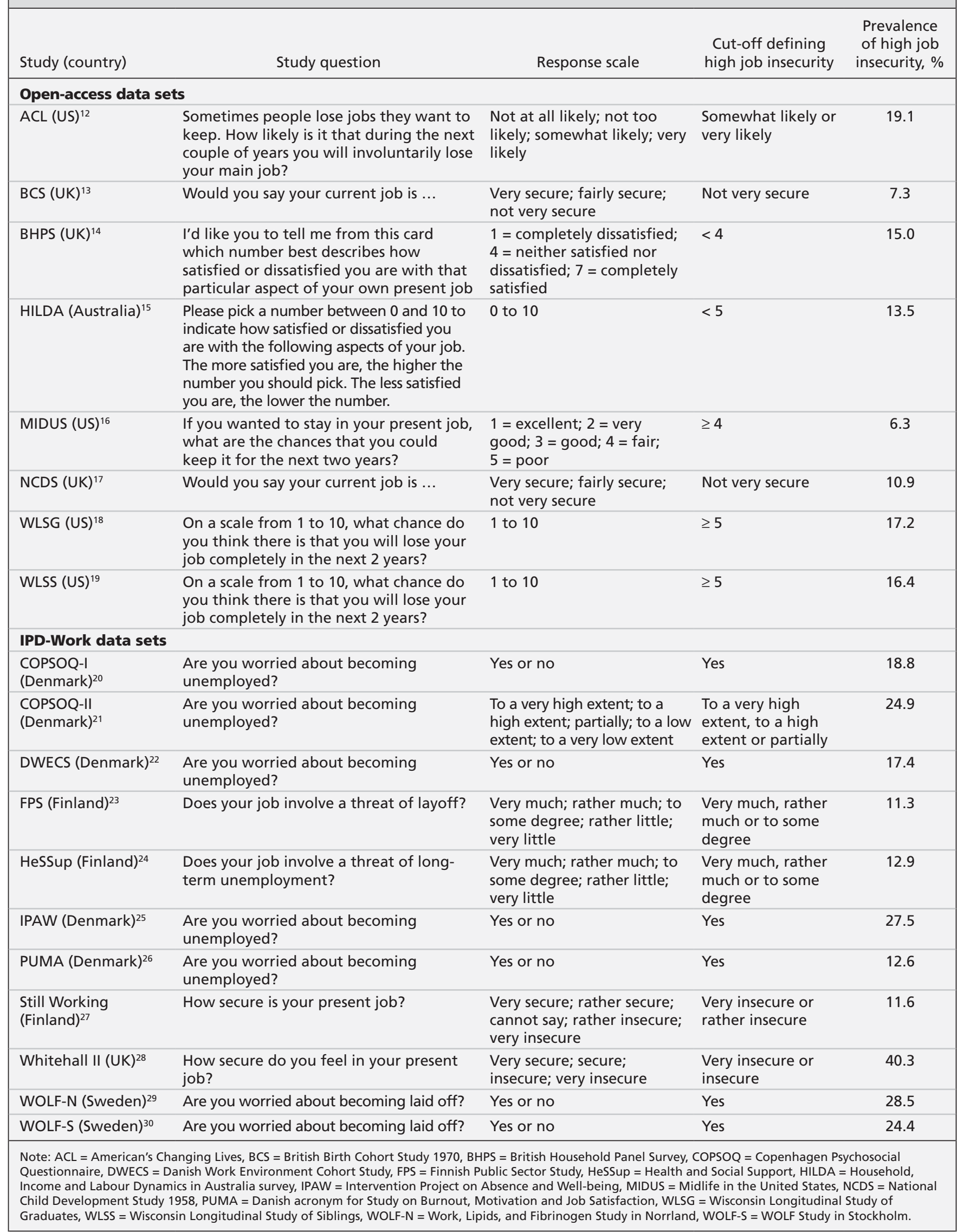




\section{Statistical analysis}

Our analyses included 19 prospective cohort studies in which job insecurity was measured once at baseline and subsequent incident diabetes was measured over the follow-up period. Because not all of the studies included an exact date of diabetes diagnosis, we used logistic regression in all studies to calculate studyspecific odds ratios (ORs) and 95\% confidence intervals (CIs) as the measure of association between job insecurity and subsequent incident diabetes. $^{33}$

Meta-analysis was used to produce a common risk estimate. ${ }^{34}$ Because there was no significant heterogeneity between the study-specific estimates, we conducted the meta-analyses using fixed-effect models. Heterogeneity of the studyspecific estimates was examined using the $I^{2}$ statistic (higher values denote greater heterogeneity). ${ }^{35}$

In the preliminary analysis, we calculated ageand sex-adjusted study-specific effect estimates of the association between job insecurity and incident diabetes. In the main analysis, we used multivariable models that were further adjusted for socioeconomic status, obesity, physical activity, alcohol use and smoking. To examine whether the association between job insecurity and incident diabetes differed between subgroups of studies and participants, we stratified the analyses by method of diabetes diagnosis (self-reported, electronic medical records or clinical examination), study quality (assessed as low or high using the Cochrane risk-of-bias tool for cohort studies, ${ }^{36}$ see Appendix 3, available at www.cmaj.ca/lookup/ suppl/doi:10.1503/cmaj.150942/-/DC1), age ( $<50 \mathrm{yr}$ or $\geq 50 \mathrm{yr}$ ), sex, socioeconomic status (low, intermediate or high) and study location (Europe or United States).

We used Stata/MP version 13.1 (StataCorp) to analyze data from the open-access data archives and to compute the results of all the metaanalyses. We used SAS version 9.2 (SAS Institute Inc.) to analyze study-specific data from the IPD-Work studies.

\section{Results}

\section{Sample characteristics}

The 8 studies from the open-access data sets included a total of 44770 working women and men with data on age, sex, socioeconomic status, job insecurity and diabetes. The 11 studies from the IPD-Work Consortium included a further 96055 working women and men with suitable data, bringing the total study population to 140825 (mean age 42.2 yr; 81816 [58.1\%] women) (Table 2). Overall, 3954 incident cases of diabetes occurred over a mean follow-up of
9.4 (range 4.0-21.1) years. Although 2 studies were started in $1986,{ }^{12,27}$ baseline assessment for the remaining studies was between 1991 and 2009. Studies were from Australia, Denmark, Finland, Sweden, the United Kingdom and the US (Table 1, Appendix 2).

\section{Association between job insecurity and incident diabetes}

The prevalence of high job insecurity ranged from $6.3 \%$ to $40.3 \%$ (Table 1). The mean incidence of diabetes per 10000 person-years ranged from 9.0 to 85.2 (Table 2).

Age- and sex-adjusted estimates of the association between job insecurity and incident diabetes for the 19 studies are presented in Figure 1A. The multivariable-adjusted analyses, additionally adjusted for socioeconomic status, obesity, physical activity, alcohol use and smoking, are presented in Figure 1B for the 15 studies with data on all covariates $(n=108525$; 2850 incident diabetes cases).

High job insecurity at baseline was associated with an increased risk of diabetes in the age- and sex-adjusted analysis compared with low job insecurity (pooled OR 1.19, 95\% CI 1.09-1.30). The effect was attenuated in the multivariableadjusted analysis but remained statistically significant (pooled OR 1.12, 95\% CI 1.01-1.24). Heterogeneity between the study-specific estimates was low to moderate (age- and sex-adjusted analysis: $P^{2}=24 \%, p=0.2$; multivariable-adjusted analysis: $I^{2}=27 \%, p=0.2$ ). Sequential adjustment of the association between job insecurity and incident diabetes for socioeconomic status and the lifestyle covariates are presented in Appendix 4 (available at www.cmaj.ca/lookup/ suppl/doi:10.1503/cmaj.150942/-/DC1).

The results of the subgroup analyses are shown in Figure 2. We found no statistically significant differences in the association between job insecurity and incident diabetes in the multivariable-adjusted analyses when stratified by method of diabetes diagnosis, study quality, age, sex, socioeconomic status or study location ( $p$ value $>0.1$ for all subgroup differences). Odds ratios for the subgroups divided by diagnosis method and study quality were identical because the diagnosis of diabetes is a key feature of highquality (electronic medical records or clinical examination [oral glucose tolerance test]) and low-quality (self-report) studies. Although the correlation between diabetes identified by selfreport and medical records is relatively high ${ }^{37}$ and the difference between the high- and low-quality studies was not statistically significant, these analyses provide stronger evidence in support of an association between job insecurity and inci- 
dent diabetes in the high-quality studies (pooled OR 1.19, 95\% CI 1.04-1.35).

Loss to follow-up ranged from less than 5\% to $34 \%$, and length of follow-up from 4 to 21 years (Appendix 2), but neither factor had an effect on the association between job insecurity and incident diabetes (Appendix 4). The rate of unemployment at baseline varied from $4.6 \%$ to $11.3 \%$ (Appendix 2), but there was no evidence that the association between job insecurity and incident diabetes differed between the cohorts (Appendix 4).

\section{Interpretation}

In our meta-analysis of individual-level data from 19 prospective cohort studies involving more than 140000 participants and close to 4000 incident cases of diabetes, we observed a $19 \%$ increase in the age- and sex-adjusted odds of incident diabetes among workers who reported high levels of job insecurity. In the 15 studies with complete covariate data, the multivariableadjusted association was attenuated to $12 \%$, but it remained statistically significant. Most of this attenuation resulted from adjustment for the lower socioeconomic status among the workers who reported job insecurity.

Because we were unable to find previous studies, either cross-sectional or longitudinal, that examined the association between job insecurity and incident diabetes, our study appears to be the first to report on this association. Our findings are congruent with those from studies showing an association between job insecurity and weight gain, ${ }^{6}$ a risk factor for diabetes, and between job insecurity and incident coronary artery disease, ${ }^{7}$ a complication of diabetes. In the latter meta-analysis of cohort studies from the IPDWork Consortium, ${ }^{7}$ employees who reported job insecurity had a $19 \%$ increase in the multivariable-adjusted odds of incident myocardial infarc-

Table 2: Characteristics of participants and assessment of incident diabetes in the included cohort studies

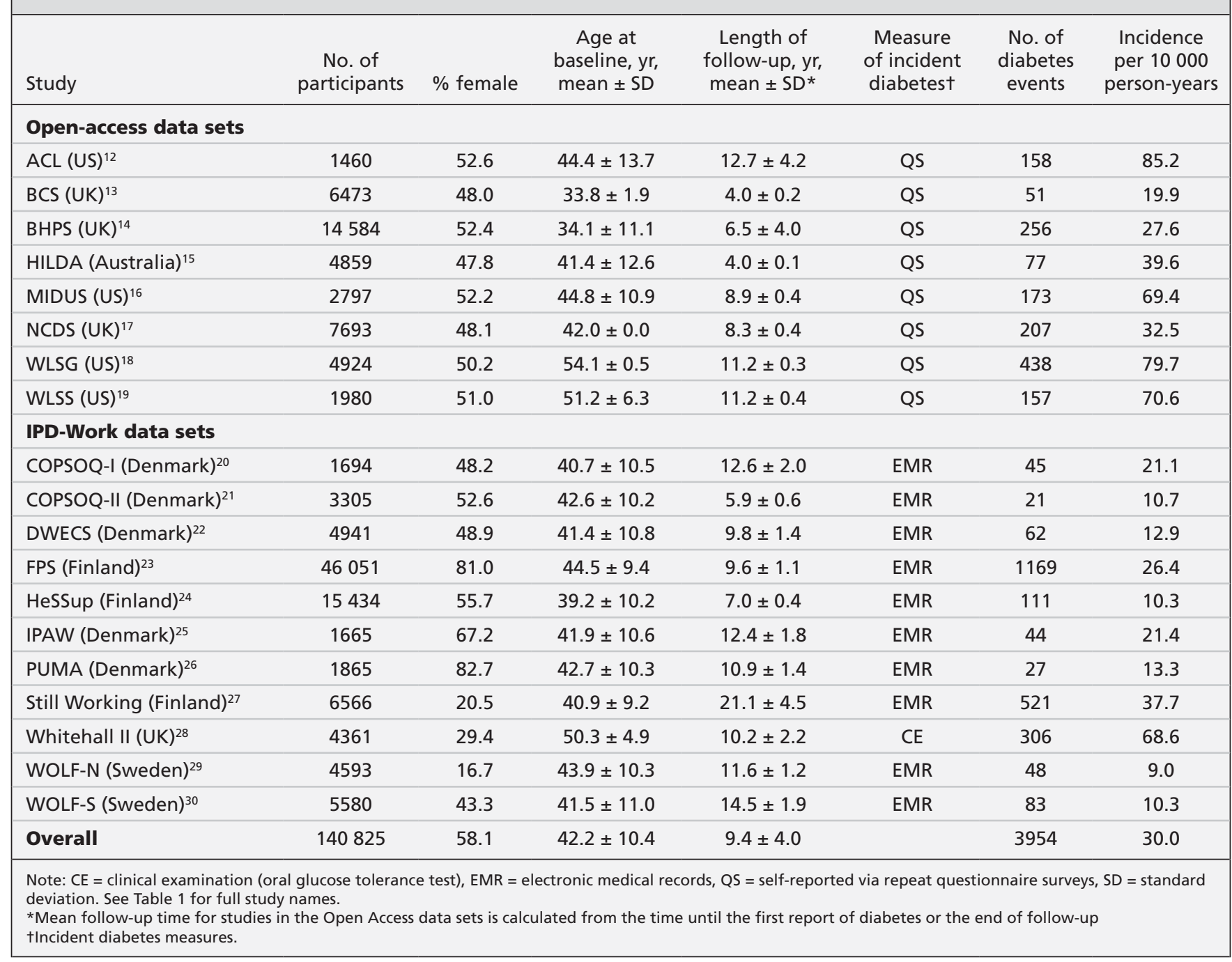


(A) Age- and sex-adjusted analysis

\begin{tabular}{|c|c|c|}
\hline Study & Events, $n / N$ & Adjusted OR $(95 \% \mathrm{C}$ \\
\hline$A C L^{12}$ & $158 / 1460$ & $0.85(0.55-1.32)$ \\
\hline $\mathrm{BCS}^{13}$ & $51 / 6473$ & $1.37(0.54-3.48)$ \\
\hline BHPS $^{14}$ & 256/14 584 & $1.34(0.99-1.81)$ \\
\hline HILDA $^{15}$ & $77 / 4859$ & $1.25(0.68-2.28)$ \\
\hline MIDUS ${ }^{16}$ & $173 / 2797$ & $0.84(0.43-1.65)$ \\
\hline $\mathrm{NCDS}^{17}$ & $207 / 7693$ & $0.74(0.45-1.21)$ \\
\hline WLSG $^{18}$ & $438 / 4924$ & $1.26(0.99-1.62)$ \\
\hline WLSS $^{19}$ & $157 / 1980$ & $0.83(0.52-1.33)$ \\
\hline COPSOQ-|'20 & $45 / 1694$ & $1.07(0.51-2.27)$ \\
\hline COPSOQ-II21 & $21 / 3305$ & $2.82(1.19-6.67)$ \\
\hline DWECS 22 & $62 / 4941$ & $0.85(0.41-1.73)$ \\
\hline FPS 23 & $1169 / 46051$ & $1.32(1.10-1.59)$ \\
\hline HeSSup 24 & $111 / 15434$ & $1.09(0.65-1.84)$ \\
\hline IPAW25 & $44 / 1665$ & $1.26(0.66-2.38)$ \\
\hline PUMA 26 & $27 / 1865$ & $2.02(0.80-5.11)$ \\
\hline Still Working27 & $521 / 6566$ & $0.96(0.72-1.28)$ \\
\hline Whitehall II28 & $306 / 4361$ & $1.21(0.95-1.53)$ \\
\hline WOLF-N ${ }^{29}$ & $48 / 4593$ & $1.10(0.56-2.14)$ \\
\hline WOLF-S 30 & $83 / 5580$ & $1.91(1.21-3.03)$ \\
\hline Overall & $3954 / 140825$ & $1.19(1.09-1.30)$ \\
\hline \multicolumn{3}{|c|}{ Heterogeneity: $R^{2}=24 \%$} \\
\hline
\end{tabular}

\section{(B) Multivariable-adjusted analysis}

\begin{tabular}{|c|c|c|}
\hline $\mathrm{ACL}^{12}$ & $158 / 1460$ & $0.76(0.48-1.20)$ \\
\hline $\mathrm{BCS}^{13}$ & $51 / 6453$ & $1.28(0.50-3.26)$ \\
\hline HILDA $^{15}$ & $69 / 4314$ & $1.18(0.62-2.25)$ \\
\hline MIDUS 16 & $160 / 2624$ & $0.94(0.45-1.97)$ \\
\hline NCDS 17 & $192 / 7500$ & $0.65(0.38-1.11)$ \\
\hline WLSG ${ }^{18}$ & $411 / 4749$ & $1.22(0.94-1.59)$ \\
\hline WLSS ${ }^{19}$ & $142 / 1816$ & $0.86(0.52-1.41)$ \\
\hline COPSOQ-II' & $21 / 3163$ & $2.30(0.94-5.60)$ \\
\hline DWECS 22 & $49 / 4492$ & $0.61(0.25-1.47)$ \\
\hline FPS 23 & $1047 / 42683$ & $1.27(1.05-1.53)$ \\
\hline HeSSup 24 & $101 / 14029$ & $0.78(0.43-1.40)$ \\
\hline IPAW25 & $33 / 1429$ & $0.90(0.41-1.98)$ \\
\hline Whitehall II28 & $291 / 4151$ & $1.08(0.86-1.36)$ \\
\hline WOLF-N29 & $46 / 4342$ & $1.16(0.59-2.29)$ \\
\hline WOLF-S 30 & $79 / 5320$ & $1.66(1.04-2.64)$ \\
\hline Overall & 2850/108 525 & $1.12(1.01-1.24)$ \\
\hline
\end{tabular}
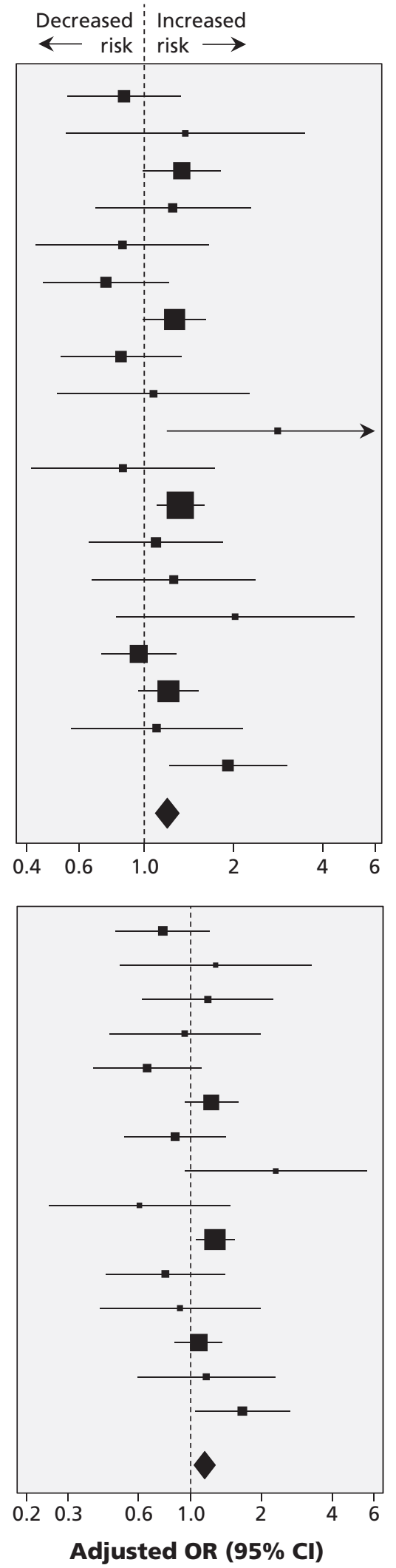

Figure 1: Study-specific analyses of association between job insecurity and incident diabetes (A) after adjustment for age and sex and (B) after adjustment for age, sex, socioeconomic status, obesity, physical activity, alcohol use and smoking. Values greater than 1.0 indicate an increased risk of incident diabetes. $\mathrm{Cl}=$ confidence interval, $\mathrm{OR}=$ odds ratio. See Table 1 for full study names. 
tion or coronary death. The strength of the association was the same as for incident diabetes in high-quality studies in the current analysis.

\section{Limitations}

Our study needs to be considered in view of several limitations. Although we were able to adjust our analyses for age, sex, socioeconomic status and obesity at baseline, data on other potential confounders and mediators, such as anxiety and weight gain over the follow-up period, were not available in most of the data sets.

We cannot claim that our analysis included all possible data. However, we were able to include a large, diverse sample of workers from 19 well-characterized prospective cohort studies that together cover the US, Australia and several European countries. Therefore, our findings are likely to apply more widely to workers in other high-income countries.

Job insecurity was measured with the use of single questions that were not uniform across the studies. In common parlance, job insecurity is understood to refer to employed workers who feel threatened by unemployment, a broad concept around which the single-item measures in our meta-analyses appear to coalesce. ${ }^{38,39}$ Low to moderate heterogeneity, as indicated by the $I^{2}$ statistics suggests effects that differ little between the studies. However, the use of single, rather than multiitem questionnaires at one point in time only to measure job insecurity may result in an underestimation of the association between job insecurity and health-related outcomes ${ }^{40}$ a limitation which may also apply to our study. Previous work has also shown that chronic or repeated exposure to job insecurity is more harmful to health than exposure to job insecurity at one point in time. ${ }^{41}$

Ascertainment of diabetes varied between the studies. Only the Whitehall II study administered a repeated oral glucose tolerance test, the gold standard. This enabled the study to detect both diagnosed and undiagnosed diabetes. The remaining studies, based on health records or self-

\begin{tabular}{|c|c|c|c|}
\hline Variable & Events, $n / N$ & $\begin{array}{c}12 \text { statistic, } \% \\
(p \text { value })\end{array}$ & Adjusted OR $(95 \% \mathrm{C}$ \\
\hline \multicolumn{4}{|c|}{ Diagnosis method } \\
\hline EMR or CE & $1667 / 79609$ & $29(p=0.2)$ & $1.19(1.04-1.35)$ \\
\hline Self-report & $1183 / 28914$ & $14(p=0.3)$ & $1.00(0.84-1.20)$ \\
\hline \multicolumn{4}{|c|}{ Study quality } \\
\hline High quality & $1667 / 79609$ & $29(p=0.2)$ & $1.19(1.04-1.35)$ \\
\hline Other & $1183 / 28914$ & $14(p=0.3)$ & $1.00(0.84-1.20)$ \\
\hline \multicolumn{4}{|l|}{ Age, yr } \\
\hline$<50$ & $1180 / 74206$ & $36(p=0.09)$ & $1.15(0.98-1.35)$ \\
\hline$\geq 50$ & $1694 / 34960$ & $0(p=0.9)$ & $1.11(0.96-1.28)$ \\
\hline \multicolumn{4}{|l|}{ Sex } \\
\hline Female & $1402 / 65448$ & $18(p=0.2)$ & $1.12(0.96-1.32)$ \\
\hline Male & $1472 / 42457$ & $25(p=0.2)$ & $1.14(0.99-1.31)$ \\
\hline \multicolumn{4}{|c|}{ Socioeconomic status } \\
\hline Low & $1008 / 28482$ & $36(p=0.08)$ & $1.09(0.92-1.30)$ \\
\hline Intermediate & $1016 / 45351$ & $0(p=0.5)$ & $1.26(1.06-1.50)$ \\
\hline High & $814 / 30330$ & $0(p=0.5)$ & $1.09(0.87-1.36)$ \\
\hline \multicolumn{4}{|l|}{ Region } \\
\hline Europe & 1910/93 562 & $38(p=0.1)$ & $1.15(1.01-1.30)$ \\
\hline United States & $871 / 10647$ & $22(p=0.3)$ & $1.04(0.85-1.26)$ \\
\hline
\end{tabular}

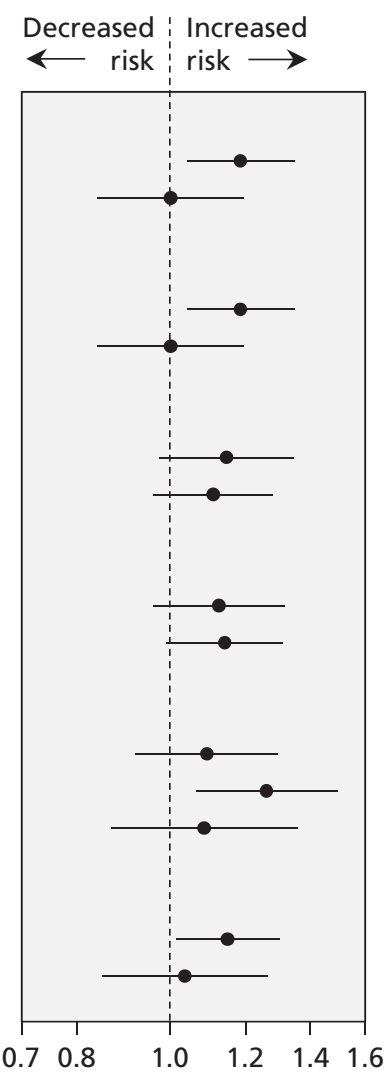

Adjusted OR (95\% Cl)

Figure 2: Subgroup analyses of association between job insecurity and incident diabetes after adjustment for age, sex, socioeconomic status, obesity, physical activity, alcohol use and smoking (15 cohorts, $n=108$ 525; 2850 incident cases of diabetes). Values greater than 1.0 indicate an increased risk of incident diabetes. $\mathrm{CE}=$ clinical examination (oral glucose tolerance test), $\mathrm{Cl}=\mathrm{confidence}$ interval, $E M R=$ electronic medical record, $O R=$ odds ratio. 
reports, will have missed undiagnosed diabetes cases. In Whitehall II, the age and sex-adjusted odds ratio for the association between job insecurity and diabetes was 1.19; the same as the overall estimate for all the studies (1.19).

\section{Conclusion}

Our findings suggest that self-reported job insecurity is associated with a modest increased risk of incident diabetes. These findings are most appropriately interpreted in a public health context in which small long-term effects on common disease outcomes can have high relevance. Ideally in such situations, policy responses should take a population-level approach to reducing exposure to job insecurity. Also, health care personnel should be aware of that workers reporting job insecurity may be at modest increased risk of diabetes.

\section{References}

1. OECD workers in the global economy: Increasingly vulnerable? In: OECD employment outlook 2007. Paris: Organisation for Economic Co-operation and Development; 2007:105-55.

2. Moynihan R. Job insecurity contributes to poor health. BMJ 2012;345:e5183.

3. Ferrie JE. Is job insecurity harmful to health? $J R$ Soc Med 2001;94:71-6

4. Laszló KD, Pikhart H, Kopp MS, et al. Job insecurity and health: a study of 16 European countries. Soc Sci Med 2010;70:867-74.

5. Kim IH, Muntaner C, Vahid Shahidi F, et al. Welfare states, flexible employment, and health: a critical review. Health Policy 2012;104:99-127.

6. Ferrie JE, Shipley MJ, Marmot MG, et al. An uncertain future: the health effects of threats to employment security in whitecollar men and women. Am J Public Health 1998;88:1030-6.

7. Virtanen M, Nyberg ST, Batty GD, et al.; IPD-Work Consortium. Perceived job insecurity as a risk factor for incident coronary heart disease: systematic review and meta-analysis. BMJ 2013, 347:f4746.

8. Danaei G, Finucane MM, Lu Y, et al.; Global Burden of Metabolic Risk Factors of Chronic Diseases Collaborating Group (Blood Glucose). National, regional, and global trends in fasting plasma glucose and diabetes prevalence since 1980: systematic analysis of health examination surveys and epidemiological studies with 370 country-years and 2.7 million participants. Lancet 2011;378:31-40.

9. Finucane MM, Stevens GA, Cowan MJ, et al.; Global Burden of Metabolic Risk Factors of Chronic Diseases Collaborating Group (Body Mass Index). National, regional, and global trends in bodymass index since 1980: systematic analysis of health examination surveys and epidemiological studies with 960 country-years and 9.1 million participants. Lancet 2011;377:557-67.

10. Colditz GA, Willett WC, Rotnitzky A, et al. Weight gain as a risk factor for clinical diabetes mellitus in women. Ann Intern Med 1995;122:481-6.

11. Chan JM, Rimm EB, Colditz GA, et al. Obesity, fat distribution, and weight gain as risk factors for clinical diabetes in men. Diabetes Care 1994;17:961-9.

12. House JS, Lantz PM, Herd P. Continuity and change in the social stratification of aging and health over the life course: evidence from a nationally representative longitudinal study from 1986 to 2001/2002 (Americans' Changing Lives Study). J Gerontol B Psychol Sci Soc Sci 2005;60:15-26.

13. Elliott J, Shepherd P. Cohort profile: 1970 British Birth Cohort (BCS70). Int J Epidemiol 2006;35:836-43.

14. Coxon APM. Sample design issues in a panel survey: the case of the British Household Panel Study. Essex (UK): Institute for Social and Economic Research; 1991.

15. Butterworth P, Crosier T. The validity of the SF-36 in an Australian National Household Survey: demonstrating the applicability of the Household Income and Labour Dynamics in Australia (HILDA) Survey to examination of health inequalities. BMC Public Health 2004:4:44.

16. Brim OF, Ryff CD. How healthy are we? A national study of wellbeing at mid-life. University of Chicago Press; Chicago: 2004.
17. Power C, Elliott J. Cohort profile: 1958 British Birth Cohort (National Child Development Study). Int J Epidemiol 2006;35: 34-41.

18. Sewell WH, Houser R. Education, occupation, and earnings: achievement in the early career. New York: Academic Press; 1975.

19. Hauser RM, Sewell WH. Birth order and educational attainment in full sibships. Am Educ Res J 1985;22:1-23.

20. Kristensen TS, Hannerz H, Hogh A, et al. The Copenhagen Psychosocial Questionnaire - a tool for the assessment and improvement of the psychosocial work environment. Scand $J$ Work Environ Health 2005;31:438-49.

21. Pejtersen JH, Kristensen TS, Borg V, et al. The second version of the Copenhagen Psychosocial Questionnaire. Scand J Public Health 2010;38:8-24.

22. Feveile H, Olsen O, Burr H, et al. Danish Work Environment Cohort Study 2005: from idea to sampling design. Stat Transit 2007;8:441-58

23. Kivimäki M, Lawlor DA, Davey Smith G, et al. Socioeconomic position, co-occurrence of behavior-related risk factors, and coronary heart disease: the Finnish Public Sector study. Am J Public Health 2007;97:874-9.

24. Korkeila K, Suominen S, Ahvenainen J, et al. Non-response and related factors in a nation-wide health survey. Eur J Epidemiol 2001;17:991-9.

25 Nielsen M, Kristensen T, Smith-Hansen L. The Intervention Project on Absence and Well-being (IPAW): design and results from the baseline of a 5-year study. Work Stress 2002;16:191-206.

26. Borritz M, Rugulies R, Bjorner JB, et al. Burnout among employees in human service work: design and baseline findings of the PUMA study. Scand J Public Health 2006;34:49-58.

27. Väänänen A, Murray M, Koskinen A, et al. Engagement in cultural activities and cause-specific mortality: prospective cohort study. Prev Med 2009;49:142-7.

28. Marmot M, Brunner E. Cohort Profile: the Whitehall II study. Int J Epidemiol 2005;34:251-6.

29. Alfredsson L, Hammar N, Fransson E, et al. Job strain and major risk factors for coronary heart disease among employed males and females in a Swedish study on work, lipids and fibrinogen. Scand J Work Environ Health 2002;28:238-48.

30. Peter R, Alfredsson L, Hammar N, et al. High effort, low reward, and cardiovascular risk factors in employed Swedish men and women: baseline results from the WOLF Study. J Epidemiol Community Health 1998;52:540-7.

31. Kivimäki M, Virtanen M, Kawachi I, et al. Long working hours, socioeconomic status, and the risk of incident type 2 diabetes: a meta-analysis of published and unpublished data from 222120 individuals. Lancet Diabetes Endocrinol 2015;3:27-34.

32. Tabák AG, Jokela M, Akbaraly TN, et al. Trajectories of glycaemia, insulin sensitivity, and insulin secretion before diagnosis of type 2 diabetes: an analysis from the Whitehall II study. Lancet 2009;373:2215-21.

33. Szumilas M. Explaining odds ratios. J Can Acad Child Adolesc Psychiatry 2010;19:227-9.

34. Deeks JJ, Higgins JPT, Altman DG, editors. Analysing data and undertaking meta-analyses. In: Higgins JPT, Green S, editors. Cochrane handbook for systematic reviews of interventions. Version 5.1.0. Oxford: Cochrane Collaboration; 2011. Available: www.handbook.cochrane.org (accessed 2016 Feb. 15).

35. Higgins JP, Thompson SG, Deeks JJ, et al. Measuring inconsistency in meta-analyses. BMJ 2003;327:557-60.

36. Higgins JPT, Green S, editors. Cochrane handbook for systematic reviews of interventions. Version 5.1.0. Oxford: Cochrane Collaboration; 2011. Available: www.handbook.cochrane.org (accessed 2016 Feb. 15)

37. Baker M, Stabile M, Deri C. What do self-reported, objective, measures of health measure? NBER Working Paper 8419. Cambridge (MA): National Bureau of Economic Research; 2001.

38. Ashford SJ, Lee C, Bobko P. Content, causes and consequences of job insecurity: a theory based measure and substantive test. Acad Manage J 1989;32:803-29.

39. Hartley J, Jacobson D, Klandermans B, et al. Job insecurity: coping with jobs at risk. London (UK): Sage Publications; 1991.

40. Sverke M, Hellgren J, Näswall K. No security: a meta-analysis and review of job insecurity and its consequences. J Occup Health Psychol 2002; 7:242-64.

41. Heaney CA, Israel BA, House JS. Chronic job insecurity among automobile workers: effects on job satisfaction and health. Soc Sci Med 1994;38:1431-7.

Affiliations: Department of Epidemiology and Public Health (Ferrie, Batty, Shipley, Tabák, Kivimäki), University College London, London, UK; School of Community and Social Medicine (Ferrie), University of Bristol, Bristol, UK; Finnish 
Institute of Occupational Health (Virtanen, Heikkilä, Koskinen, Oksanen, Pahkin, Pentti, Salo, Väänänen, Vahtera, Nyberg, Kivimäki), Helsinki, Tampere and Turku, Finland; Institute of Behavioural Sciences (Jokela, Kivimäki), University of Helsinki, Helsinki, Finland; National Research Centre for the Working Environment (Madsen, Bjorner, Rugulies), Copenhagen, Denmark; Institute of Environmental Medicine (Alfredsson, Fransson), Karolinska Institutet, Stockholm, Sweden; Centre for Occupational and Environmental Medicine (Alfredsson, Theorell, Westerlund), Stockholm County Council, Stockholm, Sweden; Centre for Cognitive Ageing and Cognitive Epidemiology (Batty), University of Edinburgh, Edinburgh, Scotland; Department of Occupational and Environmental Medicine (Borritz), Bispebjerg University Hospital, Copenhagen, Denmark; Federal Institute for Occupational Safety and Health (Bundesanstalt für Arbeitsschutz und Arbeitsmedizin) (Burr), Berlin, Germany; Institute for Medical Sociology, Medical Faculty (Dragano), University of Düsseldorf, Düsseldorf, Germany; National Institute for Health and Welfare (Elovainio), Helsinki, Finland; School of Health Sciences (Fransson), Jönköping University, Jönköping, Sweden; Stress Research Institute (Fransson), Stockholm University, Stockholm, Sweden; Department of Health Sciences (Knutsson), Mid Sweden University, Sundsvall, Sweden; Departments of Public Health (Koskenvuo) and Social Research (Kouvonen), University of Helsinki, Helsinki, Finland; Institute for Social and Economic Research (Kumari), University of Essex, Colchester, UK; Unit of Social Medicine (Nielsen), Frederiksberg University Hospital, Copenhagen, Denmark; Department of Psychology (Nordin), Umeå University, Umeå, Sweden; The Danish National Centre for Social Research (Pejtersen), Copenhagen, Denmark; Departments of Psychology (Salo) and Public Health (Suominen, Vahtera), University of Turku, Turku, Finland; Folkhälsan Research Center (Suominen), Helsinki, Finland; University of Skövde (Suominen),
Skövde, Sweden; 1st Department of Medicine (Tabák), Semmelweis University Faculty of Medicine, Budapest, Hungary; Turku University Hospital (Vahtera), Turku, Finland; Department of Medical Sciences (Westerholm), Uppsala University, Uppsala, Sweden; Departments of Public Health and Psychology (Rugulies), University of Copenhagen, Copenhagen, Denmark

Contributors: All of the authors contributed to the study concept and design and to the analysis and interpretation of data. Jane Ferrie and Marianna Virtanen undertook the literature search, and Markus Jokela searched the relevant open-access data sets. Markus Jokela and Ida Madsen performed the statistical analysis. Mika Kivimäki, Töres Theorell, Reiner Rugulies and Nico Dragano obtained funding for the IPD-Work Consortium. Jane Ferrie, Marianna Virtanen and Mika Kivimäki drafted the manuscript. All of the authors revised the manuscript critically for important intellectual content, approved the final version to be published and agreed to be guarantors of the work.

Funding: The IPD-Work Consortium is supported by NordForsk (grant no. 75021), the Nordic Programme on Health and Welfare; the EU New OSH ERA Research Programme (funded by the Finnish Work Environment Fund; the Swedish Research Council for Health, Working Life and Welfare; the German Social Accident Insurance; and the Danish National Research Centre for the Working Environment); the Academy of Finland (grant nos. 132944 and 258598); and the Bupa UK Foundation (grant no. 22094477). Mika Kivimäki is supported by the Medical Research Council (grant no. K013351) and the Economic and Social Research Council, UK. Funding bodies for the participating cohort studies are listed on their websites. The study sponsors had no role in the design of the study, the collection, analysis or interpretation of data, the writing of the report or the decision to submit the article for publication. 